\title{
The anatomical characteristics of Vietnamese adult hip joint: a multiplanar reconstruction computer tomographic study
}

\author{
D. Tran Trung ${ }^{1}$, H. Pham Trung', M. Truong Cong ${ }^{1}$, N. Maffullii, ${ }^{2,3,4}$, T. Nguyen Trung ${ }^{1}$ \\ 1 Hanoi Medical University, Vietnam \\ 2 Department of Orthopaedics and Traumatology, Azienda Ospedaliera San Giovanni di Dio e Ruggi d'Aragona, \\ University of Salerno School of Medicine, Surgery and Dentistry, Salerno, Italy \\ 3 Queen Mary University of London, Barts and the London School of Medicine and Dentistry, Centre for Sports \\ and Exercise Medicine, Mile End Hospital, London, UK \\ 4 Institute of Science and Technology in Medicine, Keele University Medical School, Stoke on Trent, UK
}

\author{
CORRESPONDING AUTHOR: \\ Nicola Maffulli \\ Department of \\ Musculoskeletal Disorders \\ Faculty of Medicine, \\ Surgery and Dentistry \\ University of Salerno \\ Via Allende, Baronissi (Salerno), Italy \\ E-mail: n.maffulli@qmul.ac.uk
}

\section{DOI:}

10.32098/mltj.02.2019.02

LEVELOF EVIDENCE:

4

\begin{abstract}
SUMMARY
Background. The present study evaluated some anatomical characteristics of the acetabulum and proximal femur in the hips of adult asymptomatic Vietnamese individuals.

Methods. We used 32 slice computed tomographic system with a multiplanar reconstruction (MPR CT) protocol to evaluate several parameters of the acetabulum and proximal femur, including Acetabular diameter (ADi), Acetabular depth (ADe), Acetabular ratio (AR, calculated by (ADe/ADi) x100), Acetabular inclination angle (AI), Acetabular anteversion angle (AA), Centre-edge angle (CE), Femoral head diameter (FDi), Femoral neck anteversion (FA), Combine anteversion angle (CA, calculated by AA + FA), Femoral shaft-neck angle $(\mathrm{SN})$, and Femoral medial offset (FO). Results. The average of parameters of ADi, ADe, AR, AI, AA, CE, FDi, FA, CA, SN, FO were $50.0 \pm 2.9 \mathrm{~mm} ; 24.3 \pm 2.2 \mathrm{~mm} ; 48.5 \pm 3.7 \mathrm{~mm} ; 38.5$ $\pm 3.9^{\circ} ; 17.2 \pm 7^{\circ} ; 38.3 \pm 6.4^{\circ} ; 44.4 \pm 2.9 \mathrm{~mm} ; 13.7 \pm 10.4^{\circ} ; 30.8 \pm 13.2^{\circ} ; 129.5 \pm 5.8^{\circ} ; 32 \pm$ $4.9 \mathrm{~mm}$, respectively. There were no significant differences between the sexes in ADi $(\mathrm{P}<$ $0.001)$, ADe $(\mathrm{P}<0.05)$, FDi $(\mathrm{P}<0.001)$. Males had significantly larger acetabula and femoral heads. There was evidence of a statistically significant negative association between age and ADi, FDi, SN $(\mathrm{P}<0.05)$. There was evidence of a statistically significant positive association between ADi and ADe $(\mathrm{P}<0.001), \mathrm{ADi}$ and FDi $(\mathrm{P}<0.001), \mathrm{AI}$ and $\mathrm{CE}(\mathrm{P}<0.05)$, $\mathrm{SN}$ and $\mathrm{FO}(\mathrm{P}<0.001)$. Conclusion. There are marked quantitative differences between hip joint parameters of healthy adult Vietnamese individuals and what is reported in other ethnic groups. These data constitute a baseline for future research related to hip joint pathology and hip joint replacement surgery in Vietnamese subjects.
\end{abstract}

KEY WORDS

hip joint; anatomy; morphology; Vietnamese subjects; hip joint arthroplasty

\section{INTRODUCTION}

The various anatomical components of the hip joint work together in a complex mechanical arrangement, allowing the hip to function in the three dimensions. A full understanding of these parameters and how they interact with each other is a key factor for successful hip arthroplasty surgery.

The development of multislice computed tomographic system (CT) with multiplanar reconstruction (MPR) and computer graphic software allows to precisely evaluate the morphology and dimensions of the acetabulum and the proximal femur. Multiplanar reconstruction CT allows to build accurate models taking into account the shape, size and motion of the hip joints in three-dimensional space, so as to predict what will occur when performing hip arthroplasty surgery. The present study evaluates some characteristics of shape, size, and orientation in space of the hip joint of Vietnamese adults using MPR CT. 


\section{MATERIALS AND METHODS}

\section{Study design and data source}

Using a cross-sectional study design, 41 patients were selected from our records. Patients had been seen in the clinic with a unilateral hip lesion, ranging from femoral neck fractures, avascular necrosis of the femoral head, or primary osteoarthritis. All patients lived in Hanoi, were skeletally mature (> 20 years old), with no structural abnormality of the spine and pelvis, and had no previous hip surgery. We collected information about age, gender, height (meter), body mass (kilogram), body mass index $\left(\mathrm{BMI}=\mathrm{W} / \mathrm{H}^{2}\right)$, diagnosis of the condition they suffered from, the affected side from medical records. The study received full ethics approval from the local ethics committee of Saint Paul University Hospital, Hanoi, Vietnam, and follows the criteria and guidelines of Muscles Ligaments and Tendons Journal $(1,2)$.

\section{Measurement Performance and Methods}

We used the Siemens SOMATOM perspective 32 slices, Siemens Healthcare GmbH, Germany CT scanner. The patient was placed supine, balanced on the plane of the table so that the superior anterior iliac spines were at the same level. The lower limbs were fully extended, and internally rotated of $10-15^{\circ}$. The measurement used a $5 \mathrm{~mm}$ slice thickness, $0.75 \mathrm{~mm}$ reconstruction, a 0.7 to $1.3 \mathrm{~mm}$ interval between each slice. The process started from the top of the pelvis to below the tibial tubercle. The beam intensity was $80-120 \mathrm{~mA}$, with a total dose of 247 $\mathrm{mGy}{ }^{*} \mathrm{~cm}$. The axial plane (AP) was defined as the vertical plane passing through the superior-anterior iliac spines, perpendicular to the axis of the body. The coronal plane (CP) was defined as the plane parallel to the body axis and the axial plane.

On MPR windows, a circle was designed to cover the femoral head, identifying the transverse section of the AP and CP, at which point the size of the acetabulum and the femoral head are the largest. On the AP, the acetabular diameter (ADi) was defined as the distance between the outermost points of the anterior and posterior collum of the acetabulum, in millimeters (Figure 1). Acetabular depth (ADe) was defined as the distance from the midpoint of the ADi line to the innermost point of the acetabulum, measured in millimeters (Figure 1). Also in this plane, based on the circle previously drawn, the femoral head diameter (FDi) was determined, in millimeters (Figure 1). The acetabular ratio (AR) was calculated using the formula $\mathrm{AR}=(\mathrm{ADe} / \mathrm{ADi}) \times 100$.

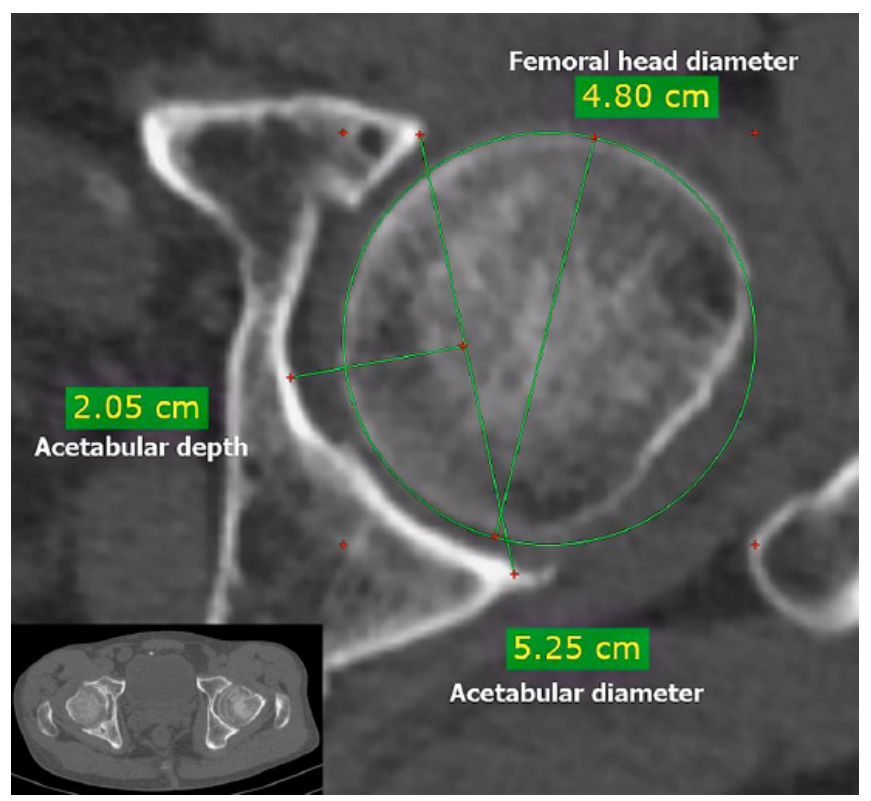

Figure 1. The Acetabular diameter (ADi), Acetabular depth $(A D e)$ and Femoral head diameter (FDi) in the axial plane

On the AP, the line connecting the posterior end of the ischial tuberosities was defined as the inter-ischial-tuberosity line. The acetabular anteversion angle (AA) was defined as the angle formed by the ADi line and the line perpendicular to the inter-ischial-tuberosity line, measured in degrees (Figure 2).

The inter-ischial-tuberosity line was identified on the CP or scout view windows. The acetabular inclination angle (AI) was defined as the angle formed by a line tangent to the lowed edge of the teardrop connecting with the outermost superior margin of the acetabulum and the inter-ischial-tuberosity line, measured in degrees. The acetabular centre-edge angle (CE) was defined as the angle formed by the line connecting the centre of the femoral head and the outermost superior margin of the acetabulum, with the line through the centre of the femoral head and perpendicular to the inter-ischial-tuberosity line, measured in degrees (Figure 3).

Using the CT overlapping technique, we identified the femoral neck anteversion angle (FA)(3). The femoral neck axis was defined as the line passing through the midpoints of the neck at the most proximal portion of the inferior aspect of the neck, on a CT slice when the head was not visible. The posterior condylar axis was defined as the line drawn along the largest femoral condyle on the CT slice. A line drawing of both proximal and distal slices was produced on two separate sheets of paper. The 


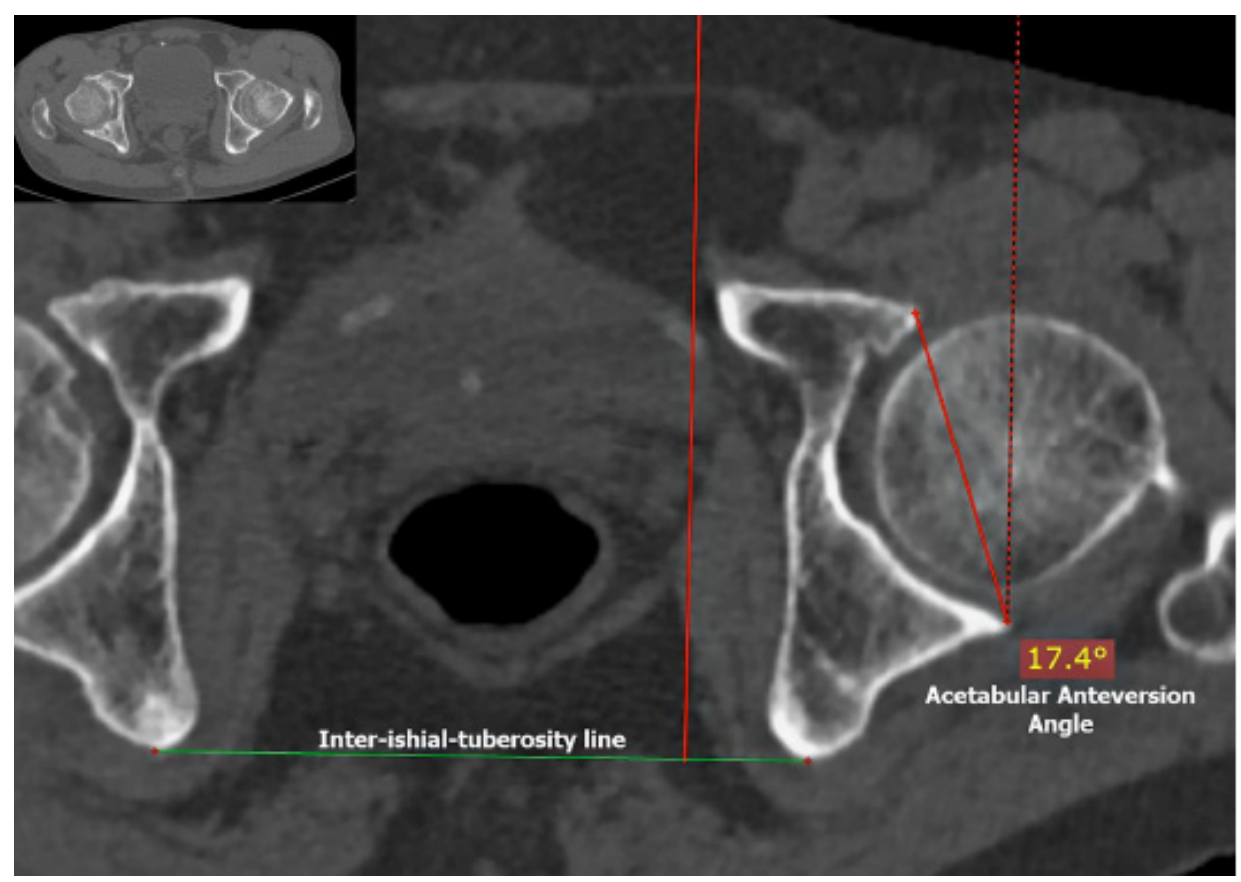

Figure 2. The Acetabular Anteversion (AA) in the axial plane

two sheets were overlapped on the same plane, and the femoral anteversion was calculated by reading the angle between the femoral neck axis and the posterior condylar axis (Figure 4). The acetabular combined anteversion angle (CA) was calculated using the formula $\mathrm{CA}=\mathrm{AA}+$ FA, measured in degrees.

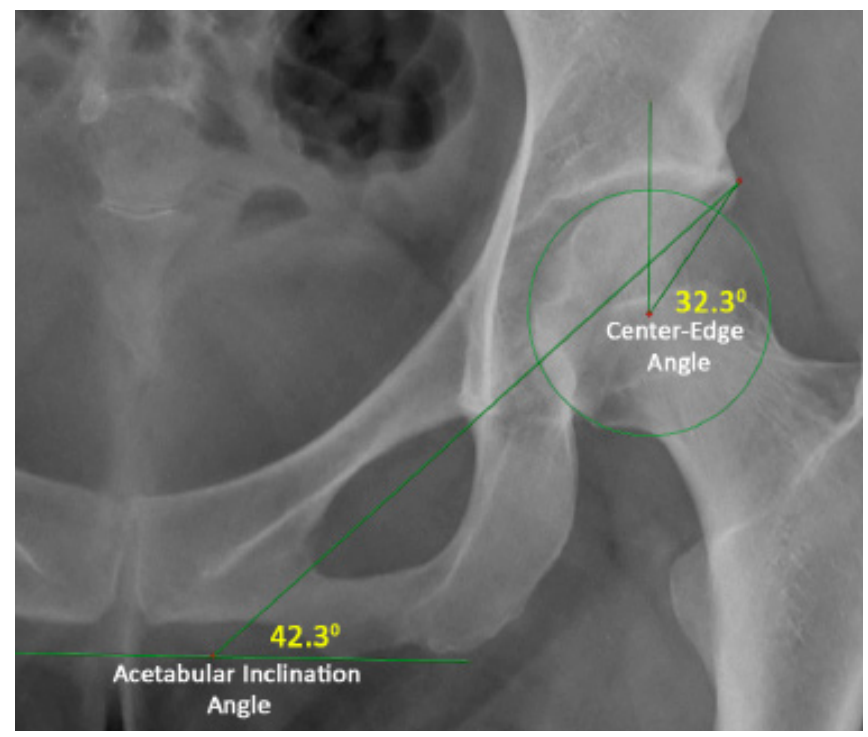

Figure 3. The Acetabular Inclination (Al) and Centre-Edge (CE) Angle in a scoutview window
On the CP, the line passing through the centre of the femoral head and the midpoint of the superior and inferior border of neck medullary canal determined the femoral neck axis. The line passing through two midpoints of the outer and inner medullary canal in the proximal one third of the femur defined the femoral shaft axis. The

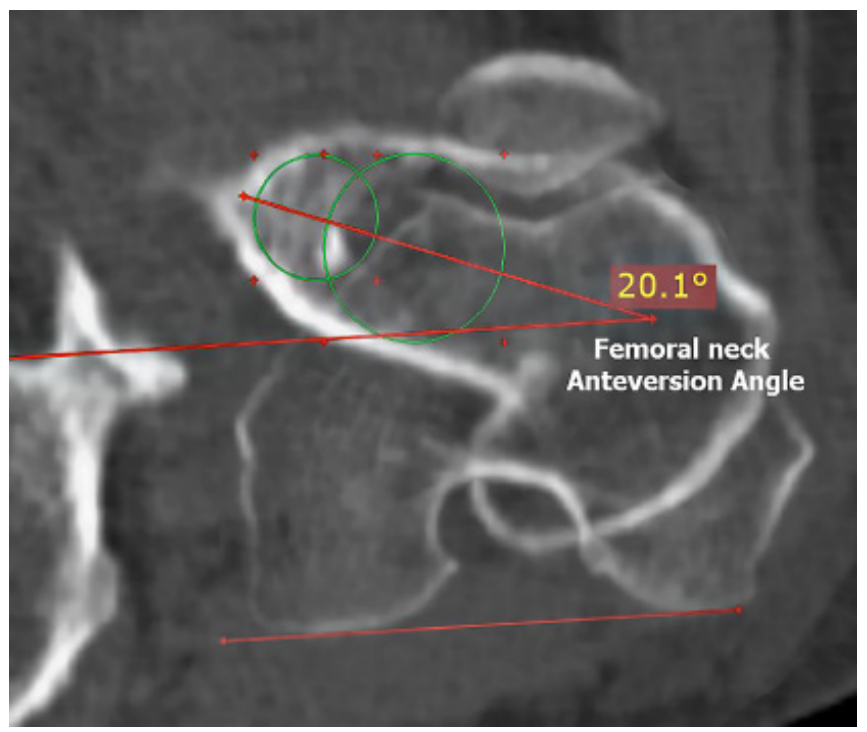

Figure 4. The Femoral neck anteversion angle (FA) in computed tomographic (CT) overlapped axial plane 
femoral shaft-neck angle (SN) was defined as the angle between the femoral neck axis and the femoral shaft axis, measured in degrees (Figure 5). The medial femoral offset (FO) was defined as the distance from the centre of the femoral head to the femoral shaft axis, measured in millimeters (Figure 5).

\section{Statistical Analysis}

The data were measured independently by two authors (D.TT and H.PT), and the mean of the results were statistically analyzed. All data were expressed as means \pm standard deviation (SD), range and distribution.

Differences were analyzed using SPSS ver. 23.0, IBM, New York statistical software. Patients were divided accord-ing to gender and hip side. Analysis of variance was used to determine significant differences $(\mathrm{P}<0.05)$ between the two groups. The F-test was used to investigate the state of dispersion. The Student t-test was used to determine signif-icant differences.

One-way ANOVA was used to analyzing the difference between mean values of the various parameters between the age and diagnostic groups. The association between the mean values of the parameters age and BMI, was tested using the bivariate association test, using Pearson correlation coefficients for standard deviation, with two-tailed significance. With quantitative variables having the same

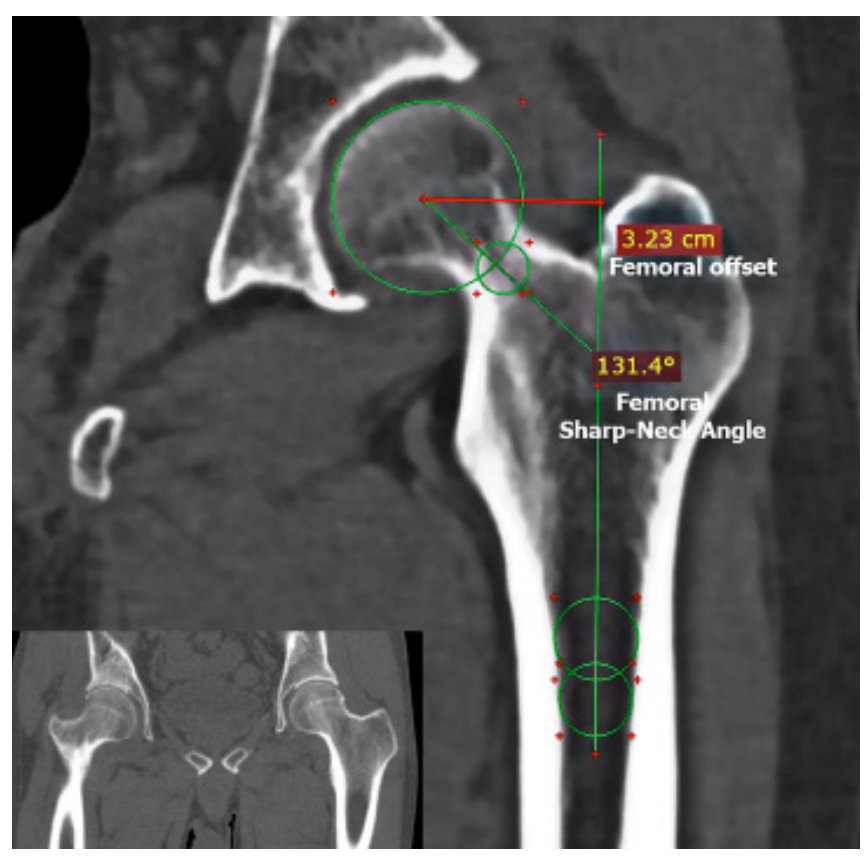

Figure 5. The Femoral shaft-neck (SN) angle and Femoral offset (FO) in the coronal plane measurement units and determined to be associated, we used linear regression test to find the correlation formula, with a confidence interval of $95 \%$.

\section{RESULTS}

A total of 41 subjects (26 males and 15 females; average age; $62.12 \pm 14.76$ years, range 20 to 91 years; mean body mass index $21.31 \pm 1.89$, range 17.58 to 27.94 ; 13 right hips and 28 left hips) were included in the present investigation. The proportion of subjects with trauma, osteonecrosis, and osteoarthritis was $21(51.2 \%), 12(29.3 \%)$ and $8(19.5 \%)$, respectively.

The morphologic parameters of the acetabulum and femur are reported in Tables Ia and $\mathbf{I b}$.

The one-way ANOVA and the Student T-test showed no significant differences between the mean of the parameters among the age groups, the diagnosis groups, and the hip side groups. Table IIa and Table IIb show the average of the various parameters in males and females. There were significant differences in acetabular diameter, acetabular depth and femoral head diameter between the sexes $(\mathrm{P}<0.001$, 0.002 and $<0.001$, respectively). The indexes for males were significantly higher, on average, than for females.

Table la. Anatomical parameters of the acetabulum in Vietnamese adults

\begin{tabular}{lllllll}
\hline & A.Di & A.De & A.R & A.I & A.A & C.E \\
\hline Mean & 50.0 & 24.3 & 48.5 & 38.5 & 17.2 & 38.3 \\
\hline $\begin{array}{l}\text { Standard } \\
\text { Deviation }\end{array}$ & 2.9 & 2.2 & 3.7 & 3.9 & 7.0 & 6.4 \\
\hline Minimum & 45.0 & 20.6 & 41.2 & 31.2 & 3.6 & 18.2 \\
\hline Maximum & 56.3 & 30.0 & 58.8 & 47.1 & 31.2 & 50.7 \\
\hline
\end{tabular}

Table Ib. Anatomical parameters of the proximal of femur in Vietnamese adults

\begin{tabular}{|c|c|c|c|c|c|}
\hline & F.Di & F.A & C.A & S.N & F.O \\
\hline Mean & 44.4 & 13.7 & 30.8 & 129.5 & 32.0 \\
\hline $\begin{array}{l}\text { Standard } \\
\text { Deviation }\end{array}$ & 2.9 & 10.4 & 13.2 & 5.8 & 4.9 \\
\hline Minimum & 38.9 & -6.2 & 6.9 & 116.0 & 24.5 \\
\hline Maximum & 49.0 & 41.0 & 68.3 & 142.0 & 45.0 \\
\hline \multicolumn{6}{|c|}{$\begin{array}{l}\text { List of the abbreviations to Table Ia and Ib: A.Di-Acetabular diameter; } \\
\text { A.De - Acetabular depth; A.R - Acetabular ratio; A.I - Acetabular inclina- } \\
\text { tion angle; A.A - Acetabular anteversion angle; C.E - Centre-edge angle; } \\
\text { F.Di - Femoral head diameter; F.A - Femoral neck anteversion; C.A - } \\
\text { Combine anteversion angle; S.N - Femoral shaft-neck angle; F.O - Femoral } \\
\text { medial offset. }\end{array}$} \\
\hline
\end{tabular}

Muscles, Ligaments and Tendons Journal 2019;9 (2) 
Table Ila. Sex-based analysis in parameters of the acetabulum in Vietnamese adult

\begin{tabular}{|c|c|c|c|c|}
\hline & Gender & Mean & Std. Deviation & $\mathbf{P}$ \\
\hline \multirow{2}{*}{ Acetabular Diameter } & Male & 51.5 & 2,4 & \multirow{2}{*}{$<0.001$} \\
\hline & Female & 47.5 & 1.6 & \\
\hline \multirow{2}{*}{ Acetabular Depth } & Male & 25.0 & 2.2 & \multirow{2}{*}{0.002} \\
\hline & Female & 22.9 & 1.4 & \\
\hline \multirow{2}{*}{ Acetabular Inclination } & Male & 38.6 & 3.8 & \multirow{2}{*}{0.825} \\
\hline & Female & 38.3 & 4.3 & \\
\hline \multirow{2}{*}{ Acetabular Anteversion } & Male & 16.3 & 7.1 & \multirow{2}{*}{0.302} \\
\hline & Female & 18.7 & 6.8 & \\
\hline \multirow{2}{*}{ Centre-Edge Angle } & Male & 38.2 & 6.4 & \multirow{2}{*}{0.897} \\
\hline & Female & 38.5 & 6.6 & \\
\hline \multirow{2}{*}{ Acetabular Ratio } & Male & 48.7 & 4.3 & \multirow{2}{*}{0.713} \\
\hline & Female & 48.2 & 2.4 & \\
\hline
\end{tabular}

Table Ilb. Sex-based analysis in parameters of the proximal of femur in Vietnamese adult

\begin{tabular}{|c|c|c|c|c|}
\hline & Gender & Mean & Std. Deviation & $\mathbf{P}$ \\
\hline \multirow{2}{*}{ Femoral head diameter } & Male & 45.9 & 2.3 & \multirow{2}{*}{$<0.001$} \\
\hline & Female & 41.8 & 1.7 & \\
\hline \multirow{2}{*}{ Shaft Neck Angle } & Male & 130.7 & 6.0 & \multirow{2}{*}{0.093} \\
\hline & Female & 127.5 & 49 & \\
\hline \multirow{2}{*}{ Femoral neck Anteversion } & Male & 13.3 & 11.7 & \multirow{2}{*}{0.749} \\
\hline & Female & 14.3 & 7.8 & \\
\hline \multirow{2}{*}{ Femoral offset } & Male & 32.5 & 5.5 & \multirow{2}{*}{0.419} \\
\hline & Female & 31.3 & 3.6 & \\
\hline \multirow{2}{*}{ Combine Anteversion Angle } & Male & 29.6 & 14.8 & \multirow{2}{*}{0.423} \\
\hline & Female & 33.0 & 9.8 & \\
\hline
\end{tabular}

The bivariate correlations test showed no evidence of a statistically significant association between the various parameters and BMI. Table 3 shown the association between parameters and age of patients, with evidence of a statistically significant negative association between acetabular diameter, femoral head diameter, femoral neck-shaft angle with age, with the correlation Pearson value was $-0.37 ;-0.34 ;-0.35$ and the $\mathrm{P}$ value was $0.016 ; 0.03 ; 0.027$, respectively.

Table III. Age-based analysis in parameters of hip joint in Vietnamese adult

\begin{tabular}{llllll}
\hline Parameter & Pearson & $\mathbf{P}$ & Parameter & Pearson & $\mathbf{P}$ \\
\hline A.Di & $-0.37^{*}$ & $\mathbf{0 . 0 1 6}$ & F.Di & $-0.34^{*}$ & $\mathbf{0 . 0 3 0}$ \\
\hline A.De & -0.29 & 0.06 & F.A & 0.27 & 0.090 \\
\hline A.R & -0.08 & 0.625 & C.A & 0.24 & 0.059 \\
\hline A.I & -0.23 & 0.143 & S.N & $-0.35^{*}$ & $\mathbf{0 . 0 2 7}$ \\
\hline A.A & 0.24 & 0.125 & F.O & -0.09 & 0.586 \\
\hline C.E & 0.09 & 0.540 & & & \\
\hline
\end{tabular}

$*$ : Significant at the 0.05 level (2-tailed).

List of the abbreviations to Table III: A.Di-Acetabular diameter; A.De-Acetabular depth; A.R - Acetabular ratio; A.I-Acetabular inclination angle; A.A - Acetabular anteversion angle; C.E - Centre-edge angle; F.Di-Femoral head diameter; F.A - Femoral neck anteversion; C.A - Combine anteversion angle; S.N-Femoral shaft-neck angle; F.O-Femoral medial offset. 
Regarding the relationship between sizes, ADi has a positive correlation with Ade, with the correlation linear equation being A.De = A. Di x $0.4+3.9 \mathrm{~mm}$. Similarly, ADi had significant positive correlation with FDi with correlation equation was A. Di = F. Di x $0.9+10.9 \mathrm{~mm}$, with the linear equation being A.De = F. Di x $0.4+14.3 \mathrm{~mm}$.

When comparing the mean of the various parameters, the bivariate correlations test and linear regression analysis showed evidence of statistically significant association between acetabular and femoral head sizes and angles of acetabular and proximal femoral. In details, there was evidence of a statistically significant positive association between Acetabular Diameter and Depth (R: 0.53, P < 0.01; linear equation: A.De $=$ A.Di x $0.4+3.9 \mathrm{~mm}$ ). There was a positive association between Acetabular diameter and Femoral head diameter ( $\mathrm{R}: 0.89, \mathrm{P}<0.001$; linear equation was: A.Di = F.Di x $0.9+10.9 \mathrm{~mm})$. There was a positive association between Acetabular inclination angle and Centre - Edge angle ( $\mathrm{R}: 0.37, \mathrm{P}=0.009$; linear equation: $\mathrm{C} . \mathrm{E}=61.2$ - A.I x 0.6 degree). There was a positive association between Acetabular depth angle and Centre - Edge angle (correlation Pearson value: 0.42, $\mathrm{P}=0.006$ ). There was evidence of a statistically significant negative association between Femoral shaft-neck angle and Femoral offset (correlation Pearson value: - 0.59, $\mathrm{P}<0.001$ ).

\section{DISCUSSION}

The average acetabular diameter in our Vietnamese subjects was $50 \pm 2.9 \mathrm{~mm}$, and the average of acetabular depth was $24.3 \pm 2.2 \mathrm{~mm}$. When compared with the investigation by Zeng et al. in 100 Chinese hip joints, their mean of acetabular diameter was greater than in our Vietnamese subjects, with $56 \mathrm{~mm}$ in males and $51.4 \mathrm{~mm}$ in females, although the acetabular depth was more shallow with $19.4 \mathrm{~mm}$ in males and $17.4 \mathrm{~mm}$ in females (4). The mean acetabular depth in the present study was similar to that reported in 266 Malaysian hip joints with $25.6 \mathrm{~mm}$ (5). The average femoral head diameter in Vietnamese subjects was $44.4 \pm 2.9 \mathrm{~mm}$, similar to what reported by Nakahara et al. in 136 Japanese hip joints at $44.9 \mathrm{~mm}$ (6). Although there was no association with BMI, the size of acetabular and femoral head of Vietnamese individuals was similar to those of other Asian ethnic groups.

Comparative analysis of data on the shape and orientation of the acetabulum in Vietnamese (Table Ia) and in other Asian ethnic groups (Table IV) revealed that the average of acetabular ratio (depth/diameter) in Vietnamese $(48.5 \pm$ $3.7 \%$ ) was higher than in Chinese subjects $(34.7 \%$ in male and $33.9 \%$ in female) (4). The average of $\mathrm{AI}\left(38.5 \pm 3.9^{\circ}\right)$ was similar to the mean of Chinese, Malaysian and Japanese people's $\left(39.5^{\circ}, 38.14^{\circ}\right.$ and 38.2 respectively) (4-6). The average of $\mathrm{AA}\left(17.2 \pm 7^{\circ}\right.$, with the wide range from $\left.3.6^{\circ}-31.2^{\circ}\right)$ was smaller than the mean of other Asian ethnic groups. (Malaysian - $19.96^{\circ}$, Japanese - 20.2 ${ }^{\circ}$, Indian - $19^{\circ}$, Chinese $\left.18.79^{\circ}\right)(5-8)$. The average CE $\left(38.3 \pm 6.4^{\circ}\right)$ was greater than mean the of Chinese population $\left(33.3^{\circ}\right.$ in male and $32.8^{\circ}$ in female) (8) and Japanese population (35.8 ) (6). The CE had a significant positive correlation with $\mathrm{AI}$ and AA. From the above data, it was possible to ascertain that the Vietnamese acetabular shape tended to be more hemispherical, with AR close to $50 \%$. At the same time, given the large CE, the coverage of the acetabulum was also greater.

The average SN in Vietnamese $\left(129.5 \pm 5.8^{\circ}\right)$, was lower than the value of Caucasian $\left(137.43^{\circ}\right)$ (9) and of Chinese $\left(133.02^{\circ}\right)(8)$ subjects, but was greater than the mean of Japa-

Table IV. Shape and orientation of the acetabulum in Vietnamese and other Asian ethnic groups.

\begin{tabular}{|c|c|c|c|c|c|c|}
\hline Population & $\begin{array}{l}\text { Acetabular } \\
\text { Ratio (AR) }\end{array}$ & $\begin{array}{l}\text { Acetabular } \\
\text { Inclination (AI) }\end{array}$ & $\begin{array}{l}\text { Acetabular } \\
\text { Anteversion (AA) }\end{array}$ & $\begin{array}{l}\text { Centre-Edge } \\
\text { Angle (CE) }\end{array}$ & $\begin{array}{l}\text { Femoral shaft- } \\
\text { neck angle } \\
(\mathrm{SN})\end{array}$ & $\begin{array}{l}\text { Femoral neck } \\
\text { anteversion (FA) }\end{array}$ \\
\hline $\begin{array}{l}\text { Vietnamese } \\
\text { (current study) }\end{array}$ & $48.5 \pm 3.7 \%$ & $38.5^{\circ} \pm 3.9^{\circ}$ & $\begin{array}{l}17.2^{\circ} \pm 7^{\circ} \\
\left(\text { range } 3.6^{\circ}-31.2^{\circ}\right)\end{array}$ & $38.3^{\circ} \pm 6.4^{\circ}$ & $129.5^{\circ} \pm 5.8^{\circ}$ & $\begin{array}{l}13.7^{\circ} \pm 10.4^{\circ} \\
\left(\text { range } 6.2^{\circ}-\right. \\
41.00 \text { ) }\end{array}$ \\
\hline $\begin{array}{l}\text { Chinese }\left(\mathrm{AR} \text { and } \mathrm{AI}^{4} \text {; }\right. \\
\left.\mathrm{AA}, \mathrm{CE}, \mathrm{SN} \text { and } \mathrm{FA}^{8}\right)\end{array}$ & $\begin{array}{l}34.7 \% \text { in male, } \\
33.9 \% \text { in female }\end{array}$ & $39.5^{\circ}$ & $18.79^{\circ}$ & $\begin{array}{l}33.3^{\circ} \text { in male, } \\
32.8^{\circ} \text { in } \\
\text { female }\end{array}$ & $133.02^{\circ}$ & $10,62^{\circ}$ \\
\hline Japanese $^{6}$ & - & $38.2 \pm 4.1$ & $20.2^{\circ}$ & $35.8^{\circ} \pm 6.0^{\circ}$ & $125.1^{\circ}$ & $22.4^{\circ}$ \\
\hline Malaysian & - & $38.14^{\circ}$ & $19.96^{\circ}$ & - & - & - \\
\hline Indian $^{7}$ & - & - & $19^{\circ}$ & - & - & $8^{\circ}$ \\
\hline Caucasian $^{9}$ & - & - & $\begin{array}{l}17.20^{\circ} \text { in male, } \\
22.59^{\circ} \text { in female }\end{array}$ & - & $137.43^{\circ}$ & - \\
\hline
\end{tabular}


nese subjects $\left(125.1^{\circ}\right)$ (6). The average of FO in Vietnamese subjects was $32 \pm 4.9 \mathrm{~mm}$, with evidence of a statistically significant negative association between $\mathrm{SN}$ and FO. SN and FO have an important role in balancing the moment arm of the hip: the change in $\mathrm{SN}$ and FO values after hip replacement surgery can directly affect the gait of the patient and the weight bearing function of the prosthetic hip. Applied to the conditions in Vietnam, most of the manufacturer's use the stem type with $\mathrm{SN}$ was $135^{\circ}$. Hence, after hip arthroplasty, this will exert a direct impact on the weight bearing system of the hip. Therefore, it may well be necessary to undertake specific studies to design hip arthroplasty devices more appropriate to the anatomical characteristics of Vietnamese people.

The average FA and CA in Vietnamese were $13.7 \pm 10.4^{\circ}$ (range from $6.2^{\circ}$ to $41.0^{\circ}$ ) and $30.8 \pm 13.2^{\circ}$ (range from $6.9^{\circ}$ to $\left.68.3^{\circ}\right)$. Compared with other studies, the FA of Vietnamese subjects was higher than that of Indian $\left(8^{\circ}\right)(7)$ and Chinese $\left(10,62^{\circ}\right)(8)$, but lower than the value of Japanese subjects $\left(22.4^{\circ}\right)^{6}$. The combine angle anteversion is the sum of AA and FA: this angle represents the relative motion between acetabulum and femoral head. Several authors have proposed equations to use $\mathrm{CA}$ as a criterion for orientation of prosthetic components to avoid dislocation and impingement. Widmer et al recommended that the CA should be $37.3^{\circ}$ (10); Dorr et al suggested that it should be $37.6 \pm 7^{\circ}$ (11); Nakashima et al. recommend a CA of 40-60 (12). In our study, although both CA and FA had high variability, the average of them were still in the same range as the other studies. Thus, in hip replacement surgery, anatomical parameters of the hip could be used to determine the optimal location of the hip joint components. However, to confirm this, more research about the combine anteversion angle is needed.

Tables IIa and IIlb show that the average of the diameter and the depth of acetabulum in males were significantly greater than the average in females $(51.5 \pm 2.4 \mathrm{~mm}$ versus $47.5 \pm 1.6 \mathrm{~mm}, \mathrm{P}<0.001$, and $25.0 \pm 2.2 \mathrm{~mm}$ versus $22.9 \pm$ $1.4 \mathrm{~mm}, \mathrm{P}=0.002$, respectively). Similarly, the average of femoral head diameter in males was higher than in females $(45.9 \pm 2.3 \mathrm{~mm}$ versus $41.8 \pm 1.7 \mathrm{~mm}, \mathrm{P}<0.001)$. However, according to our data, the average acetabular anteversion angle in Vietnamese males was lower than that of females $\left(16.3^{\circ}\right.$ versus $\left.18.7^{\circ}\right)$, similar to what found in other studies $(4,6,8-9)$ (Table V). There was no significant difference between the sexes in other variables.

The equations developed can be applied to templating for hip arthroplasty surgery, based on the femoral head diameter measured on plain radiographs or directly during the procedure, so as to estimate the diameter and depth of acetabulum used during surgery.

We acknowledge that our study has limitations. For example, we are aware that the sample studies is relatively small, and thus may not be representative of the entire Vietnamese population. In addition, the study was performed on patients with unilateral hip ailments, and we did not perform a comparison with a healthy population. However, our ethics committee did not allow us to use radiography in asymptomatic individuals for the sole purpose of measuring the variables studies in the present investigation. Finally, the imaging assessment undertaken in the present study does not allow to produce an accurate evaluation in the three dimensions.

The present investigation evidences statistically significant negative association between patient's age and ADi, FDi and $\mathrm{SN}$, respectively, one can assume that the higher the age of the patient, the lower the bone quality and the consequent bone loss, resulting in the reduction of the diameter of the acetabulum and the femoral head. At the same time, weight bearing of the femoral neck was reduced, thereby lowering the SN. However, this assumption needs empirical support.

\section{CONCLUSION}

The dimensional variables of normal hip joints in Vietnamese adults were similar to those described in other Asian populations, but the acetabular shape was more hemispherical and covered a larger area when compared to Japanese and Chinese subjects. The femoral shaft-neck angle is lower, but the medial offset and the combined anteversion angle were not higher. These values were within the limits reported in other studies. The peculiarity of the anatomi-

Table V. Acetabular anteversion angles in Vietnamese and other ethnic groups by sex

\begin{tabular}{ccccccc}
\hline \multirow{2}{*}{ Gender } & \multicolumn{5}{c}{ Average acetabular anteversion angle } \\
\cline { 2 - 7 } & $\begin{array}{c}\text { Vietnamese } \\
(\text { current study) }\end{array}$ & $\begin{array}{c}\text { Chinese } \\
(\text { Zeng, 2012) }\end{array}$ & $\begin{array}{c}\text { Chinese } \\
(\text { Jiang, 2015) }\end{array}$ & $\begin{array}{c}\text { Japanese } \\
\text { (Nakahara, 2011) }\end{array}$ & $\begin{array}{c}\text { Caucasian } \\
(\text { Atkinson, 2010) }\end{array}$ & $\begin{array}{c}\text { USA } \\
(\text { Maruyama, 2001) }\end{array}$ \\
\hline Male & $16.3^{\circ}$ & $16.0^{\circ}$ & $18.27^{\circ}$ & $17.8^{\circ}$ & $17.2^{\circ}$ & $18.15^{\circ}$ \\
\hline Female & $18.7^{\circ}$ & $17.6^{\circ}$ & $20.44^{\circ}$ & $23^{\circ}$ & $22.59^{\circ}$ & $21.3^{\circ}$ \\
\hline
\end{tabular}


cal characteristics described could be used to determine the orientation of the prosthetic component during total hip arthroplasty surgery in Vietnamese subjects.

\section{Conflict of Interest}

The authors declare that they have no conflict of interest

\section{REFERENCES}

1. Padulo J, De Giorgio A, Oliva F, Frizziero A, Maffulli N. I performed experiments and I have results. Wow, and now? Muscles Ligaments Tendons J. 2018 Jan 10; 7(3): 403-410.

2. Padulo J, Oliva F, Frizziero A, Maffulli N. Muscles, Ligaments and Tendons Journal - Basic principles and recommendations in clinical and field Science Research: 2018 update. MLTJ 2018; 8(3): 305 - 307.

3. Sugano N, Noble PC, Kamaric E. A comparison of alternative methods of measuring femoral anteversion. Journal of computer assisted tomography 1998; 22(4): 610-614.

4. Zeng Y, Wang Y, Zhu Z, Tang T, Dai K, Qiu S. Differences in acetabular morphology related to side and sex in a Chinese population. Journal of anatomy 2012; 220(3): 256-262.

5. Khalid MSM, Yunus R. Multiplanar Reconstructed Ct Study of Normal Acetabulum-inclination Angle, Anteversion Angle and Acetabular Depth (Doctoral dissertation, Universiti Sains Malaysia) 2012

6. Nakahara I, Takao M, Sakai T, Nishii T, Yoshikawa H, Sugano $\mathrm{N}$. Gender differences in 3D morphology and bony impingement of human hips. Journal of Orthopaedic Research 2011; 29(3): 333-339.

7. Maheshwari AV, Zlowodzki MP, Siram G, Jain AK. Femoral neck anteversion, acetabular anteversion and combined anteversion in the normal Indian adult population: A computed tomographic study. Indian Journal of orthopaedics 2010; 44(3): 277.

8. Jiang, N, Peng L, Al-Qwbani M, Xie GP, Yang QM, Chai Y, ... Yu B. Femoral version, neck-shaft angle, and acetabular anteversion in Chinese Han population: a retrospective analysis of 466 healthy adults. Medicine 2015; 94(21).

9. Atkinson HD, Johal KS, Willis-Owen C, Zadow S, Oakeshott RD. Differences in hip morphology between the sexes in patients undergoing hip resurfacing. Journal of orthopaedic surgery and research 2010; 5(1): 76.

10. Widmer KH, Zurfluh B. Compliant positioning of total hip components for optimal range of motion. Journal of Orthopaedic Research 2004; 22(4): 815-821.

11. Dorr LD, Malik A, Dastane M, Wan Z. Combined anteversion technique for total hip arthroplasty. Clinical orthopaedics and related research 2009; 467(1): 119-127.

12. Nakashima Y, Hirata M, Akiyama M, Itokawa T, Yamamoto T, Motomura G, ... Iwamoto Y. Combined anteversion technique reduced the dislocation in cementless total hip arthroplasty. International orthopaedics 2014; 38(1): 27-32. 